\title{
Influência da Temperatura Ambiente sobre o Desempenho e os Parâmetros Fisiológicos de Leitoas dos 30 aos 60 kg1
}

\author{
Sandra Lúcia da Silva Tavares ${ }^{2}$, Rita Flávia Miranda de Oliveira ${ }^{3}$, Juarez Lopes Donzele ${ }^{3}$, \\ Aloízio Soares Ferreira ${ }^{3}$
}

\begin{abstract}
RESUMO - Foram avaliados dados fisiológicos e de desempenho de 100 leitoas mestiças, 50 mantidas em ambiente de termoneutralidade $\left(21,4 \pm 1,00^{\circ} \mathrm{C}\right)$ e 50 em ambiente de alta temperatura $\left(32,0 \pm 0,88^{\circ} \mathrm{C}\right)$, distribuídas em delineamento de blocos ao acaso, com cinco repetições e dois animais por unidade experimental, recebendo rações com cinco níveis de energia digestível, (3100, 3250, 3400, 3550 e $3700 \mathrm{kcal}$ de $\mathrm{ED} / \mathrm{kg}$ de ração). Os animais que foram expostos à temperatura de $32^{\circ} \mathrm{C}$ tiveram ganhos de peso e consumos de ração, proteína e energia reduzidos. Conversão alimentar, eficiências de utilização de proteína e energia, relações peso jejum/PV e peso carcaça/ peso jejum e taxa de deposição de proteína não foram influenciados pelo ambiente. A taxa de deposição de gordura aumentou em razão do aumento na temperatura ambiente. O peso dos órgãos internos, com exceção do estômago, decresceu e a freqüência respiratória e temperatura retal aumentaram nos animais mantidos à temperatura de $32^{\circ} \mathrm{C}$. Os animais mantidos sob estresse de calor apresentaram valores de conversão alimentar e taxa de deposição de proteína similares aos dos animais mantidos no ambiente termoneutro, embora tenham apresentado menores consumo de ração e ganho de peso.
\end{abstract}

Palavras-chave: estresse de calor, leitoas mestiças, peso de órgãos, termoneutralidade

\section{Influence of the Environmental Temperature on the Performance and on the Physiological Parameters of Female Piglets from 30 to $60 \mathrm{~kg}$}

\begin{abstract}
Performance and physiological data from 100 crossbred female piglets, 50 maintained in a termoneuter environment $\left(21.4 \pm 1.00^{\circ} \mathrm{C}\right)$ and 50 in a high temperature environment $\left(32.0 \pm .88^{\circ} \mathrm{C}\right)$, allotted to a randomized blocks design, with five replicates and two animals per experimental unit, fed diets with five levels of digestible energy (3100, 3250, 3400, 3550 and $3700 \mathrm{kcal}$ of dietary ED/ $\mathrm{kg}$ ), were evaluated. The animals which were exposed to the temperature of $32^{\circ} \mathrm{C}$ had reduced weight gains and feed, protein and energy intakes. The environment did not influence the feed:gain ratio, the efficiencies of protein and energy utilization, the fast weight/LW ratio, the carcass weight/fast weight ratio and the protein deposition rate. The fat deposition rate increased as the environment temperature increased. The internal organ weights, except for the stomach, decreased and the breathing frequency and rectal temperature increased in the animals maintained under the temperature of $32^{\circ} \mathrm{C}$. The animals maintained at $32^{\circ} \mathrm{C}$ showed feed:gain ratio and protein deposition rate similar to animals under termoneutral environment, however had lower feed intake and weight gain.
\end{abstract}

Key Words: heat stress, crossbred female piglets, organ weight, termoneutral environment

\section{Introdução}

$\mathrm{O}$ animal reage ao ambiente térmico por meio de processos fisiológicos para manter a homeotermia. Nos suínos a dissipação de calor corporal ocorre, principalmente, por evaporação no trato respiratório. Desse modo, segundo HERZ e STEINHAUF (1978), em altas temperaturas ambiente, verifica-se o aumento da atividade respiratória do animal apenas quando outros mecanismos são ineficientes na manutenção da homeotermia e, quando a atividade respiratória se torna ineficiente, a temperatura corporal eleva-se influenciando o consumo de ração e a atividade da tireóide.
Diversos autores citados por FIALHO (1994) afirmaram que o ambiente térmico no qual o suíno é mantido influencia o consumo voluntário de ração, o ganho de peso, a eficiência alimentar e a composição da carcaça. Temperaturas ambiente acima do limite superior de termoneutralidade ocasionam redução no consumo voluntário de alimentos, na tentativa de reduzir a taxa metabólica, com subseqüente redução na taxa de ganho de peso e, geralmente, decréscimo na eficiência alimentar (JENSEN, 1991).

De acordo com FIALHO (1994), a redução do consumo de ração pelo animal, em razão do estresse de calor, requer o aumento dos níveis de nutrientes 
nas rações. A incorporação de gordura às rações pode amenizar os feitos de calor sobre os suínos, ao proporcionar redução na taxa de produção de calor corporal, devido ao seu baixo incremento calórico.

O presente trabalho foi conduzido com o objetivo de avaliar os efeitos de ambientes térmicos constantes $\left(21\right.$ ou $\left.32^{\circ} \mathrm{C}\right)$ sobre o desempenho e os parâmetros fisiológicos de leitoas dos 30 aos $60 \mathrm{~kg}$, recebendo rações com diferentes níveis de energia digestível.

\section{Material e Métodos}

Foram avaliados dados de 100 leitoas mestiças (Landrace $\mathrm{x}$ Large White), sendo que 50 foram mantidas em ambiente de termoneutralidade e $50 \mathrm{em}$ ambiente de estresse de calor, com pesos iniciais médios de 30,1 $\pm 1,79 \mathrm{~kg}$ e 30,9 $\pm 2,09 \mathrm{~kg}$, respectivamente. Os animais foram distribuídos em delineamento de blocos ao acaso, com cinco repetições e dois animais por unidade experimental, sendo que em cada ambiente receberam rações experimentais com cinco diferentes níveis de energia digestível (3100, $3250,3400,3550$ e $3700 \mathrm{kcal} / \mathrm{kg}$ de ração). Na formação dos blocos, foi adotado o critério de peso inicial e grau de parentesco.

A temperatura média interna da sala no ambiente de calor foi mantida por meio de um conjunto de seis aquecedores, tipo campânula de resistência, ligados a um termostato regulado para a temperatura de $32^{\circ} \mathrm{C}$, enquanto no ambiente de termoneutralidade a manutenção da temperatura foi feita por meio de dois aparelhos de ar-condicionado ligados a um termostato regulado para a temperatura de $22^{\circ} \mathrm{C}$.

Os termostatos e os equipamentos de medição das variáveis ambientais (termômetros de bulbo seco e bulbo úmido, de máxima e mínima e de globo negro) foram instalados em uma gaiola vazia no centro da sala a uma altura correspondente à dos animais. As leituras dos instrumentos foram realizadas às 8 e $16 \mathrm{~h}$, diariamente.

As condições térmicas médias da sala observadas durante o período experimental foram de $21,4 \pm 1,00^{\circ} \mathrm{C}$ e $32,0 \pm 0,88^{\circ} \mathrm{C}$ de temperatura do ar; $75,8 \pm 6,56 \%$ e $75,0 \pm 6,52 \%$ de umidade relativa do ar; $21,7 \pm 0,91^{\circ} \mathrm{C}$ e $31,9 \pm 0,83^{\circ} \mathrm{C}$ de temperatura de globo negro e $69,0 \pm 1,09$ e 82,9 $\pm 1,14$ de Índice de Temperatura de Globo e Umidade, respectivamente, nos ambientes de termoneutralidade e de calor.

A cada sete dias foram medidas a temperatura retal de todos os animais, pela manhã $(8 \mathrm{~h})$ e à tarde $(15 \mathrm{~h})$, e a freqüência respiratória às $8 \mathrm{~h}$, em cada ambiente. A temperatura retal foi medida por meio de um termôme- tro clínico, durante 1 minuto, enquanto a freqüência respiratória foi obtida por meio da contagem dos movimentos do flanco do animal, por um minuto.

As rações experimentais (Tabela 1) e a água foram fornecidas à vontade. As sobras de ração foram pesadas semanalmente e os animais, no início e no fim do experimento, quando atingiram, em média, $60,8 \pm 4,40 \mathrm{~kg}$ e $59,7 \pm 3,72 \mathrm{~kg}$, respectivamente, no ambiente de 21 e $32^{\circ} \mathrm{C}$, para determinação das variáveis de desempenho.

No final de cada período experimental, após jejum alimentar de 24 horas, todos os animais foram abatidos e após a pesagem as metades direitas das carcaças foram trituradas em "cutter" comercial de $30 \mathrm{HP}$ e $1775 \mathrm{rpm}$, para retirada de amostras. Um grupo adicional de dez leitoas, sendo cinco com peso médio de $30,3 \pm 0,94 \mathrm{~kg}$ e cinco com $29,5 \pm 0,82 \mathrm{~kg}$, respectivamente, para o ambiente termoneutro e de calor, foi abatido para determinação da composição inicial das carcaças. $\mathrm{O}$ abate dos animais e o processamento das carcaças, para obtenção de amostras, foram realizados de acordo com metodologia descrita por DONZELE et al. (1992). As taxas de deposição de proteína e gordura nas carcaças foram calculadas comparandose as composições das carcaças dos animais do início com aquelas do final do experimento.

As amostras de carcaça pré-secas em estufa de ventilação forçada $\mathrm{a} \pm 60^{\circ} \mathrm{C}$, por 96 horas, foram prédesengorduradas pelo método a quente no extrator tipo "Soxhlet", durante 5 horas, para posterior moagem e análise de gordura e proteína, conforme recomendações de SILVA (1990).

Em todos os animais do experimento, após o abate, foram retirados fígado, pulmões, estômago, rins, coração e intestino delgado, que foram lavados e dependurados em ganchos, à sombra, para, depois de escorrido bem o sangue, proceder à pesagem dos órgãos. No fígado foram feitos cortes para melhor escorrimento do sangue.

As análise estatísticas das variáveis de desempenho, taxas de deposição de proteína e gordura nas carcaças e pesos dos órgãos foram realizadas por intermédio do programa ANOVAG, contido no pacote computacional SAEG (Sistema para Análises Estatísticas e Genéticas), desenvolvido pela Universidade Federal de Viçosa - UFV (1982), conforme o modelo estatístico:

em que

$$
Y_{i j k}=\mu+A_{i}+E_{j}+B_{k}+A_{i j}+e_{i j k}
$$

$\mathrm{Y}_{\mathrm{ijk}}=$ ganho de peso, consumo de ração, conversão alimentar, taxas de deposição de proteína e gordura, freqüência respiratória, temperatura retal e 
Rev. bras. zootec.

Tabela 1 - Composição das dietas experimentais (\%)

Table 1 - Composition of the experimental diets

\begin{tabular}{|c|c|c|c|c|c|}
\hline \multirow[t]{2}{*}{$\begin{array}{l}\text { Ingrediente (\%) } \\
\text { Ingredient }\end{array}$} & \multicolumn{5}{|c|}{$\begin{array}{c}\text { Nível de energia digestível }(\mathrm{kcal} / \mathrm{kg}) \\
\text { Digestible energy level }\end{array}$} \\
\hline & 3100 & 3250 & 3400 & 3550 & 3700 \\
\hline Milho & 54,19 & 54,19 & 54,19 & 54,19 & 54,19 \\
\hline Corn & & & & & \\
\hline Farelo de soja & 22,26 & 22,26 & 22,26 & 22,26 & 22,26 \\
\hline $\begin{array}{l}\text { Soybean meal } \\
\text { Farelo de trigo } \\
\text { Wheat bran }\end{array}$ & 10,00 & 10,00 & 10,00 & 10,00 & 10,00 \\
\hline $\begin{array}{l}\text { Fosfato bicálcico } \\
\text { Dicalcium phosphate }\end{array}$ & 1,10 & 1,10 & 1,10 & 1,10 & 1,10 \\
\hline Calcário & 0,90 & 0,90 & 0,90 & 0,90 & 0,90 \\
\hline $\begin{array}{l}\text { Limestone } \\
\text { Mistura mineral }^{1} \\
\text { Mineral mix }\end{array}$ & 0,10 & 0,10 & 0,10 & 0,10 & 0,10 \\
\hline $\begin{array}{l}\text { Mistura vitamínica }{ }^{2} \\
\text { Vitamin mix }\end{array}$ & 0,10 & 0,10 & 0,10 & 0,10 & 0,10 \\
\hline $\begin{array}{l}\text { Sal } \\
\text { Salt }\end{array}$ & 0,34 & 0,34 & 0,34 & 0,34 & 0,34 \\
\hline $\begin{array}{l}\text { BHT } \\
\text { Óleo de soja }\end{array}$ & $\begin{array}{l}0,01 \\
0,50\end{array}$ & $\begin{array}{l}0,01 \\
2,50\end{array}$ & $\begin{array}{l}0,01 \\
4,50\end{array}$ & $\begin{array}{l}0,01 \\
7,00\end{array}$ & \\
\hline $\begin{array}{l}\text { Soybean oil } \\
\text { Amido }\end{array}$ & 4,41 & 4,17 & 3,92 & 2,60 & 0,86 \\
\hline $\begin{array}{l}\text { Corn starch } \\
\text { Areia lavada }\end{array}$ & 6,09 & 4,33 & 2,58 & 1,40 & 0,44 \\
\hline $\begin{array}{l}\text { Calculated composition } \\
\text { Composição calculada } \\
\end{array}$ & & & & & \\
\hline $\begin{array}{l}\text { Washed sand } \\
\text { Energia digestível (kcal/kg) } \\
\text { Digestible energy }\end{array}$ & 3100 & 3250 & 3400 & 3550 & 3700 \\
\hline $\begin{array}{l}\text { Proteína bruta }(\%) \\
\text { Crude protein }\end{array}$ & 16,50 & 16,50 & 16,50 & 16,50 & 16,50 \\
\hline $\begin{array}{l}\text { Lisina }(\%) \\
\text { Lysine }\end{array}$ & 0,84 & 0,84 & 0,84 & 0,84 & 0,84 \\
\hline $\mathrm{Ca}(\%)$ & 0,68 & 0,68 & 0,68 & 0,68 & 0,68 \\
\hline $\mathrm{P}(\%)$ & 0,54 & 0,54 & 0,54 & 0,54 & 0,54 \\
\hline $\begin{array}{l}{ }^{1} \text { Mistura mineral, } \mathrm{kg}^{1} \text { (Mineral m } \\
1.000 \mathrm{~g} \text {. } \\
2 \text { Mistura vitamínica por kg (Vitami } \\
5 \mathrm{~g} \text {; Vit. } \mathrm{B}_{6}, 5 \mathrm{~g} \text {; Vit. } \mathrm{B}_{12}, 40 \mathrm{mg} ; \\
\text { de sódio (sodium selenite), } 50 \mathrm{mg} \\
{ }^{3} \text { Composição calculada segundo } \\
{ }^{3} \text { Calculated composition according t }\end{array}$ & $\begin{array}{l}\text { g; Cu, } \\
\text { it. A, } 9.0 \\
\text { tênico ( } \\
\text { nte q.s.p } \\
\text { NO et al. } \\
\text { vo et al. }\end{array}$ & $\begin{array}{l}4 \mathrm{~g} ; \mathrm{N} \\
\text { Vit. } \mathrm{D} \\
\text { acid), } \\
\text { o.), } 1.0\end{array}$ & $\begin{array}{l}\text { Zn, } 14 \\
\text { Ul; Vit. } \\
\text { lo nicotí }\end{array}$ & $\begin{array}{l}\text { g; e ex } \\
\text { UI; Vit. } \\
\text { tinic acid }\end{array}$ & $\begin{array}{l}\text { q.s.p. } \\
\text {; Vit. } B_{2} \\
\text { selenito }\end{array}$ \\
\hline
\end{tabular}

peso dos órgãos referentes ao nível de energia $\mathrm{j}$, na temperatura ambiente i e no bloco k;

$\mu \quad=$ média geral da variável;

$\mathrm{A}_{\mathrm{i}}=$ efeito da temperatura ambiente $\mathrm{i}$;

$\mathrm{E}_{\mathrm{j}} \quad=$ efeito do nível de energia digestível $\mathrm{j}$, sendo

$\mathrm{j}=3100,3250,3400,3550$ e $3700 \mathrm{kcal} / \mathrm{kg}$ de ração;

$\mathrm{B}_{\mathrm{k}}=$ efeito do bloco $\mathrm{k}$, sendo $\mathrm{k}=1,2,3,4$ e 5;

$\mathrm{AE}_{\mathrm{ij}}=$ efeito da interação nível de energia $\mathrm{x}$ temperatura ambiente $\mathrm{e}$

$\mathrm{e}_{\mathrm{ijk}}=$ erro aleatório associado a cada observação.

\section{Resultados e Discussão}

Os resultados de desempenho e consumos de proteína e energia diários das leitoas dos 30 aos $60 \mathrm{~kg}$ de peso, mantidas em ambiente de termoneutralidade $\left(21,4 \pm 1,00^{\circ} \mathrm{C}\right)$ e de calor $\left(32,0 \pm 0,88^{\circ} \mathrm{C}\right)$, são apresentados na Tabela 2. Não se observou interação entre a temperatura ambiente e os níveis de energia da ração para os parâmetros avaliados. Observou-se influência da temperatura ambiente sobre o ganho de peso diário (GPD) e o consumo de ração (CR), que 


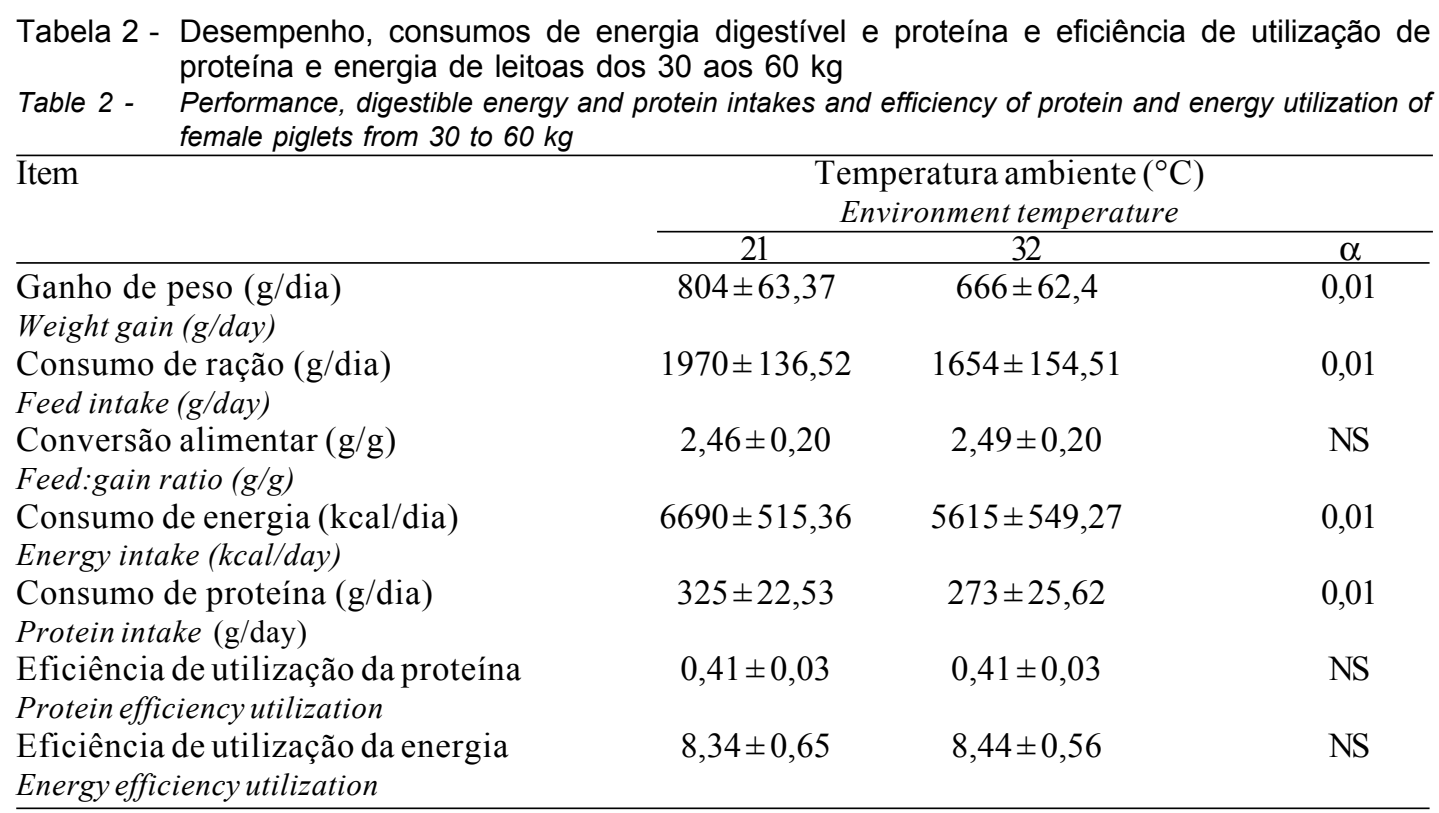

foram, respectivamente, 20,69 e 19,10\% menores $(\mathrm{P}<0,01)$ no ambiente de calor. Diversos autores (STAHLY e CROMWELL, 1979; STAHLY et al., 1979; DIVIDICH e NOBLET, 1986; LOPEZ et al.,1991; SCHENCK et al., 1992; e OLIVEIRA, 1996) também observaram redução no ganho de peso e no consumo de ração de suínos expostos à alta temperatura ambiente.

Segundo FORBES (1995), suínos mantidos em condições de estresse de calor, por reduzirem seus consumos de ração, como forma de diminuir a produção de calor associada à digestão, à absorção e ao metabolismo do alimento, reduzem a taxa de crescimento.

A conversão alimentar não variou em razão dos diferentes ambientes, indicando que a redução verificada no GPD dos animais expostos ao calor estava relacionada à ocorrida no consumo de ração. De forma similar, STAHLY et al. (1979), DIVIDICH e NOBLET (1986), SCHENCK et al. (1992) e OLIVEIRA (1996) não observaram variação na CA de suínos, em diferentes fases de crescimento, em razão da alta temperatura ambiente.

Conforme STAHLY e CROMWELL (1979), a redução no consumo de ração dos suínos submetidos ao estresse de calor resulta em depressão na taxa de crescimento, com variações mínimas na eficiência de utilização do alimento. Entretanto, CHRISTON (1988) observou piora na eficiência de utilização dos alimentos por suínos em crescimento devido ao ambiente tropical.

Constatou-se redução $(\mathrm{P}<0,01)$ nos consumos de proteína $(\mathrm{CPD})$ e energia digestível (CED) diários dos animais expostos à temperatura ambiente de $32^{\circ} \mathrm{C}$. Considerando que as rações foram isoprotéicas e que os níveis de energia foram similares nos dois ambientes, o fato de o consumo de ração dos animais sob estresse de calor ter diminuído justifica estes resultados.

Apesar das reduções observadas no CPD e no CED dos animais submetidos à temperatura de $32^{\circ} \mathrm{C}$, não se observou variação nas eficiências de utilização da proteína e energia, expressas em consumo de proteína e energia por grama de GPD (Tabela 2). Estes resultados são similares aos observados por OLIVEIRA (1996), em trabalho conduzido com leitoas dos 15 aos $30 \mathrm{~kg}$, expostas a $32^{\circ} \mathrm{C}$, e divergem dos obtidos por STAHLY e CROMWELL (1979), que observaram redução na eficiência de utilização da energia de suínos em crescimento, quando a temperatura variou de 10 a $35^{\circ} \mathrm{C}$.

O fato de a eficiência de utilização da energia não ter variado entre os ambientes indicou que os animais expostos à temperatura de $32^{\circ} \mathrm{C}$ foram capazes de se ajustarem fisiologicamente, compensando o efeito negativo da alta temperatura sobre o consumo de energia digestível.

Os dados das relações peso após jejum/peso vivo (PJ/PV) e peso carcaça/peso após jejum (PC/PJ) e das taxas de deposição de gordura e proteína na carcaça são mostrados na Tabela 3. Não se observou interação entre o ambiente e o nível de energia da ração para os parâmetros avaliados. A maior relação $\mathrm{PJ} / \mathrm{PV}(\mathrm{P}<0,03)$ observada nos animais expostos ao 
Rev. bras. zootec.

Tabela 3 - Relação peso após jejum/PV (PJ/PV) e peso carcaça/peso após jejum (PC/PJ) e taxas de deposição de proteína e gordura na carcaça de leitoas dos 30 aos $60 \mathrm{~kg}$

Table 3 - Weight after fasting $L W$ ratio (FW/LW) and carcass weight/weight after fasting ratio (CW/FW) and protein and fat deposition rate in the carcass of female piglets from 30 to $60 \mathrm{~kg}$

\begin{tabular}{lccc}
\hline Item & \multicolumn{3}{c}{ Temperatura ambiente $\left({ }^{\circ} \mathrm{C}\right)$} \\
& 21 & 32 & $\alpha$ \\
\cline { 2 - 4 } & $95,02 \pm 1,04$ & $95,49 \pm 1,00$ & 0,03 \\
Relação PJ/PV $(\mathrm{kg} / \mathrm{kg})$ & $78,27 \pm 2,06$ & $79,04 \pm 3,35$ & 0,06 \\
$\begin{array}{l}F W / \mathrm{L} W \text { ratio } \\
\text { Relação PC/PJ }(\mathrm{kg} / \mathrm{kg})\end{array}$ & & & \\
$\begin{array}{l}\text { CW/FW ratio } \\
\text { Taxa de deposição na carcaça (g/dia) }\end{array}$ & & & $\mathrm{NS}$ \\
$\begin{array}{l}\text { Deposition rate in the carcass (g/day) } \\
\text { Proteína }\end{array}$ & $93 \pm 17,21$ & $92 \pm 8,63$ & 0,01 \\
$\begin{array}{l}\text { Protein } \\
\text { Gordura } \\
\text { Fat }\end{array}$ & $208 \pm 51,79$ & $180 \pm 53,43$ & \\
\hline
\end{tabular}

Tabela 4 - Pesos absolutos e relativos, expressos como porcentagem da carcaça, dos órgãos de leitoas dos 30 aos $60 \mathrm{~kg}$

Table 4 - Absolute and relative weights, express as carcass percentage of piglets organs from 30 to $60 \mathrm{~kg}$

\begin{tabular}{|c|c|c|c|}
\hline \multirow[t]{2}{*}{$\overline{\text { Item }}$} & \multicolumn{3}{|c|}{$\begin{array}{c}\text { Temperatura ambiente }\left({ }^{\circ} \mathrm{C}\right) \\
\text { Environment temperature }\end{array}$} \\
\hline & 21 & 32 & $\alpha$ \\
\hline \multirow{2}{*}{\multicolumn{4}{|c|}{$\begin{array}{l}\text { Peso absoluto (g) } \\
\text { Absolute weight }\end{array}$}} \\
\hline & & & \\
\hline Fígado & $1206 \pm 144,09$ & $1050 \pm 99,21$ & 0,01 \\
\hline \multicolumn{4}{|l|}{ Liver } \\
\hline Pulmões & $448 \pm 57,51$ & $398 \pm 56,21$ & 0,01 \\
\hline \multicolumn{4}{|l|}{ Lungs } \\
\hline Estômago & $347 \pm 61,59$ & $331 \pm 47,04$ & NS \\
\hline \multicolumn{4}{|l|}{ Stomach } \\
\hline Rins & $234 \pm 32,39$ & $200 \pm 19,79$ & 0,01 \\
\hline \multicolumn{4}{|l|}{ Kidneys } \\
\hline Coração & $241 \pm 50,00$ & $195 \pm 27,42$ & 0,01 \\
\hline \multicolumn{4}{|l|}{ Heart } \\
\hline Intestino delgado & $1180 \pm 119,06$ & $1055 \pm 99,67$ & 0,01 \\
\hline \multicolumn{4}{|l|}{ Small intestine } \\
\hline \multicolumn{4}{|l|}{ Peso relativo (\%) } \\
\hline \multicolumn{4}{|l|}{ Relative weight } \\
\hline Fígado & $2,57 \pm 0,29$ & $2,34 \pm 0,21$ & 0,01 \\
\hline \multicolumn{4}{|l|}{ Liver } \\
\hline Pulmões & $0,97 \pm 0,13$ & $0,88 \pm 0,15$ & 0,01 \\
\hline \multicolumn{4}{|l|}{ Lungs } \\
\hline Estômago & $0,74 \pm 0,13$ & $0,73 \pm 0,12$ & NS \\
\hline \multicolumn{4}{|l|}{ Stomach } \\
\hline Rins & $0,50 \pm 0,05$ & $0,44 \pm 0,04$ & 0,01 \\
\hline \multicolumn{4}{|l|}{ Kidneys } \\
\hline Coração & $0,52 \pm 0,10$ & $0,43 \pm 0,07$ & 0,01 \\
\hline \multicolumn{4}{|l|}{ Heart } \\
\hline Intestino delgado & $2,51 \pm 0,24$ & $2,34 \pm 0,27$ & 0,01 \\
\hline Small intestine & & & \\
\hline
\end{tabular}


calor pode estar relacionada ao possível menor conteúdo de digesta no trato gastrintestinal, em razão do menor consumo de ração (STAMATARIS et al., 1991; BIKKER et al., 1995) associado ao tamanho dos órgãos internos (Tabela 4).

A temperatura ambiente influenciou $(\mathrm{P}<0,06)$ a relação $\mathrm{PC} / \mathrm{PJ}$, que foi $1,07 \%$ maior nas leitoas mantidas no ambiente de calor. Estes resultados podem estar associados aos menores pesos dos órgãos avaliados.

De forma similar, OLIVEIRA (1996) observou aumento nas relações $\mathrm{PJ} / \mathrm{PV}$ e PC/PJ de leitoas dos 15 aos $30 \mathrm{~kg}$ mantidas a $32^{\circ} \mathrm{C}$, em comparação àquelas mantidas sob temperatura de $22^{\circ} \mathrm{C}$.

Não foi observada influência da temperatura sobre a taxa de deposição de proteína (TDP) na carcaça dos animais, apesar da redução ocorrida no consumo de proteína dos animais expostos à temperatura de $32^{\circ} \mathrm{C}$. De forma similar, STAHLY e CROMWELL (1979), DIVIDICH et al. (1987) e OLIVEIRA (1996) não observaram variação na TDP na carcaça de suínos, submetidos aos ambientes térmicos de termoneutralidade e de estresse de calor, em diferentes fases de crescimento.

Diferentes autores, citados por SCHENCK et al. (1992), relataram que a deposição de proteína na carcaça de suínos em crescimento independe das condições climáticas, desde que o consumo de aminoácidos e/ou energia não se tornem limitantes.

Relacionando os valores das relações $\mathrm{PC} / \mathrm{PJ}$ e $\mathrm{PJ} / \mathrm{PV}$ com os da taxa de deposição de proteína, pode-se deduzir que a provável menor demanda de proteína dos órgãos dos animais expostos ao calor, em razão de seus menores pesos, contribuiu para que a TDP não variasse entre os ambientes, apesar do menor consumo de proteína apresentado pelos animais estressados pelo calor.

A temperatura ambiente influenciou $(\mathrm{P}<0,01)$ a taxa de deposição de gordura (TDG) na carcaça de leitoas mantidas na temperatura de $32^{\circ} \mathrm{C}$, que reduziu em 10,68\%. HOLMES (1973) relatou que a redução da retenção de energia pelos suínos expostos a altas temperaturas deve-se, principalmente, a aumento na produção de calor desses animais. Os resultados obtidos neste trabalho podem ser explicados pelo maior consumo de ração e, conseqüentemente, de energia ocorrido no ambiente de termoneutralidade $\left(21^{\circ} \mathrm{C}\right)$ e confirmam os observados por CAMPBELL e TAVERNER (1988) e OLIVEIRA (1996). Segundo CLOSE e STANIER (1984) e SPEER (1991), a deposição de gordura corporal está fortemente associada ao consumo de energia e à temperatura ambiente.
Os resultados de desempenho e carcaça corroboram o relato de diversos autores citados por STAHLY et al. (1979), os quais observaram que a taxa de crescimento é reduzida em razão do menor consumo voluntário de alimentos dos suínos expostos ao estresse de calor, enquanto a eficiência de utilização do alimento e as características de carcaça de suínos, recebendo ração à vontade, não são influenciadas.

Foi observada variação $(\mathrm{P}<0,01)$ nos pesos absoluto e relativo dos órgãos, com exceção do estômago, em razão da temperatura ambiente (Tabela 4). Não houve interação entre ambiente e nível de ED da ração para os parâmetros avaliados. Os animais mantidos em ambiente de calor apresentaram órgãos menores que os de animais mantidos em termoneutralidade, com redução variando de 10,6 (intestino delgado) a 19,4\% (coração), em peso absoluto, e de 6,8 (intestino delgado) a 17,3\% (coração), em peso relativo. DAUNCEY et al. (1983), NIENABER et al. (1987) e OLIVEIRA (1996), conduzindo experimentos com leitões dos 15 aos 64 dias de idade e leitoas dos 43 aos $86 \mathrm{~kg}$ e dos 15 aos $30 \mathrm{~kg}$ de peso, respectivamente, observaram redução nos pesos dos órgãos torácicos e abdominais dos animais expostos a ambiente quente.

Entretanto, DAUNCEY et al. (1983) relataram que a observação de órgãos mais pesados em ambiente de frio, provavelmente, se deve à influência do maior consumo de alimentos. Diferentes autores (STAMATARIS et al., 1991; RAO e McCRAKEN, 1992; e BIKKER et al., 1995) observaram redução de tamanho de órgãos somente quando a variação da ingestão de energia digestível foi superior a $15 \%$. Como neste trabalho a diferença no consumo de energia correspondeu a $19,1 \%$, pode-se inferir que, além da temperatura, o consumo de energia também influenciou o menor peso dos órgãos.

A redução no peso dos órgãos, principalmente os metabolicamente ativos (fígado e intestino), observada nos animais expostos a $32^{\circ} \mathrm{C}$ pode ser considerada um mecanismo de termorregulação utilizado na tentativa de reduzir a produção de calor corporal e, assim, contribuir para a manutenção na eficiência de utilização da energia para crescimento. Segundo KOONG et al. (1982), existe correlação positiva entre o peso de órgãos e a produção de calor de suínos em jejum e mantidos na termoneutralidade.

Com relação às respostas fisiológicas de freqüência respiratória e temperatura retal (manhã e tarde) apresentadas pelos animais, constatou-se aumento $(\mathrm{P}<0,01)$ dessas variáveis em razão do aumen- 
Rev. bras. zootec.

Tabela 5 - Variáveis fisiológicas de leitoas dos 30 aos $60 \mathrm{~kg}$

Table 5 - Physiological variables of female piglets from 30 to $60 \mathrm{~kg}$

\begin{tabular}{|c|c|c|c|}
\hline \multirow[t]{2}{*}{ Item } & \multicolumn{3}{|c|}{$\begin{array}{c}\text { Temperatura ambiente }\left({ }^{\circ} \mathrm{C}\right) \\
\text { Environment temperature }\end{array}$} \\
\hline & 21 & 32 & $\alpha$ \\
\hline Freqüência respiratória (mov/min) & $39 \pm 5,7$ & $79 \pm 15,4$ & 0,01 \\
\hline Breathing frequency & & & \\
\hline Temperatura retal manhã $\left({ }^{\circ} \mathrm{C}\right)^{*}$ & $39,4 \pm 0,18$ & $39,6 \pm 0,21$ & 0,01 \\
\hline $\begin{array}{l}\text { Rectal temperature in the morning } \\
\text { Temperatura retal tarde }\left({ }^{\circ} \mathrm{C}\right)^{*} \\
\text { Rectal temperature in the evening }\end{array}$ & $39,4 \pm 0,19$ & $39,6 \pm 0,46$ & 0,01 \\
\hline
\end{tabular}

to na temperatura ambiente de 21 para $32^{\circ} \mathrm{C}$ (Tabela 5). Estes resultados são semelhantes aos obtidos por CLOSE (1971), HOLMES (1973), CHRISTON (1988) e LOPEZ et al. (1991), trabalhando com suínos em diferentes fases de crescimento. Não foi observada diferença entre as temperaturas retal medidas nos períodos da manhã e da tarde, provavelmente, devido às condições experimentais de temperatura relativamente constante.

Embora tenha havido diferença estatística, a variação de somente $0,2^{\circ} \mathrm{C}$ na temperatura retal não foi suficiente para caracterizar dificuldade na manutenção da homeotermia, estando os valores obtidos de temperatura retal, nos dois ambientes, dentro da faixa de temperatura corporal de 39,0 a $40,0^{\circ} \mathrm{C}$, considerada normal para o suíno (BIANCA, 1968). Dessa forma, fica evidente que o aumento de $102 \%$ na freqüência respiratória dos animais mantidos no ambiente de calor permitiu que estes mantivessem a temperatura retal dentro dos níveis normais. Assim, pode-se inferir que os mecanismos fisiológicos utilizados pelas leitoas no ambiente de estresse foram eficientes na manutenção da temperatura corporal.

\section{Conclusões}

Os animais mantidos na temperatura ambiente média de $32^{\circ} \mathrm{C}$ apresentaram ajustes fisiológicos que permitiram a manutenção da conversão alimentar, das eficiências de utilização de proteína e energia da ração e da taxa de deposição de proteína em níveis similares ao dos animais expostos ao ambiente de $21^{\circ} \mathrm{C}$. No entanto, a redução do consumo de ração proporcionou menor ganho de peso nos animais mantidos no calor.

\section{Referências Bibliográficas}

BIKKER, P., KARABINAS, V., VERSTENGEN, M. W. A. et al. 1995. Protein and lipid accretion in body components of growing gilts (20 to 45 kilograms) as affected by energy intake. J. Anim. Sci., 73(8):2355-2363.

BIANCA, W. 1968. Thermoregulation. In:HAFEZ, E.S.E. Adaptation of domestic animals. Philadelphia: Lea \& Febiger. p.97-118.

CAMPBELL, R.G., TAVERNER, M.R. 1988. Relationships between energy intake and protein and energy metabolism, growth and body composition of pigs kept at 14 or $32^{\circ} \mathrm{C}$ from 9 to $20 \mathrm{~kg}$. Lvstck. Prod. Sci., 18(3-4):289-303.

CLOSE, W.H. 1971. The influence of environmental temperature and plane of nutrition on heat losses from individual pigs. Anim. Prod., 13(2):295-302.

CLOSE, W.H., STANIER, M.W. 1984. Effects of plane nutrition and environmental on the growth and development of the early-weaned piglet. 2. Energy metabolism. Anim. Prod., $38(2): 221-231$.

CHRISTON, R. 1988. The effect of tropical ambient temperature on growth and metabolism in pigs. J. Anim. Sci., 66(12):3112-3123.

DAUNCEY, M.J., INGRAM, D.L., WALTERS, D.E. et al. 1983. Evaluation of the effects of environmental temperature and nutrition on growth and development. J. Agric. Sci., 101(2):291-299.

DIVIDICH, J.L., NOBLET, J. 1986. Effect of dietary energy level on the performance of individually housed early-weaned piglets in relation to environmental temperature. Lvstck. Prod. Sci., 14(3):255-263.

DIVIDICH, J.L., NOBLET, J., BIKAWA, T. 1987. Effect of environmental temperature and dietary energy concentration on the performance and carcass characteristics of growingfinishing pigs fed to equal rate of gain. Lvstck. Prod. Sci., $17(3): 235-246$.

DONZELE, J. L., COSTA, P. M. A., ROSTAGNO, H. S. et al. 1992. Efeitos de níveis de energia digestíveis na composição da carcaça de suínos de cinco a quinze quilos. R. Soc. Bras. Zootec., 21(6):1100-1106.

FIALHO, E. T. Influência da temperatura ambiental sobre a utilização da proteína e energia em suínos em crescimento e terminação. In SIMPÓSIO LATINO-AMERICANO DE NUTRIÇÃO DE SUÍNOS, 1994, São Paulo. Anais ... São Paulo : CBNA, 1994. p. 63-83.

FORBES, J.M. 1995. Voluntary food intake and diet selection in farm animals. CAB International. 531p.

HERZ, A., STEINHAUF, D. 1978. The reaction of domestic animals to the heat stress. An. Res. Devel., 7:7-38.

HOLMES, C.W. 1973. The energy and protein metabolism of pigs growing at a high ambient temperature. Anim. Prod., 16(2):117-133.

JENSEN, A.H. 1991. Environment and management factors that influence swine nutrition. In: MILLER, E.R., ULLREY, E.D., LEWIS, A.J. Swine nutrition. Butterworth-Heinemann, 
p.387-399.

KOONG, L.J., NIENABER, J.A., PEKAS, J.C. et al. 1982. Effects of plane of nutrition on organ size and fasting heat production in pigs. J. Nutr., 112(8):1638-1642.

LOPEZ, J., JESSE, G.W., BECKER, B.A., ELLERSIECK, M.R. 1991. Effects of temperature on the performance of finishing swine. I. Effects of a hot, diurnal temperature on average daily gain, feed intake and feed efficiency. J. Anim. Sci., 69(5):1843-1849.

NIENABER, J.A, HAHN, G.L., YEN, J.T. 1987, Thermal environment on growing-finishing swine. Part II - carcass composition and organ weights. Trans. ASAE, 30(6):1776-1779.

OLIVEIRA, R.F.M. Efeito do nivel de energia digestivel e da temperatura ambiente sobreo desempenhoe sobreos parâmetros fisiológicos e hormonal de suinos dos 15 aos $30 \mathrm{~kg}$. Viçosa, MG: UFV, 1996. 150p. Tese (Doutorado emZootecnia)-Universidade Federal de Viçosa, 1996.

RAO, D.S., McCRACKEN, K.J. 1992. Energy:protein interactions in growing boars of high genetic potential for len growth. 1. Effects on growth, carcass characteristics and organ weights. Anim. Prod., 54(1):75-82.

SCHENCK, B.C., STAHLY, T.S., CROMWELL, G.L. 1992. Interactive effects of thermal environmental and dietary lisine and fat levels on rate, efficiency, and composition of growth of weanling pigs. J. Anim. Sci., 70(12):3791-3802.

SILVA, D.J. 1990. Análise de alimentos (Métodos químicos e biológicos). Viçosa - MG: UFV, Impr. Univ., 166p.

SPEER, V.C. 1991. Maximizing lean tissue growth: genetic, nutritional, and environmental factors. In: MILLER, E.R., ULLREY, E.D., LEWIS, A.J. Swine nutrition. ButterworthHeinemann. p.91-102.

STAHLY, T.S., CROMWELL, G.L. 1979. Effect of environmental temperature and dietary fat supplementation on the performance and carcass characteristics of growing and finishing swine. J. Anim. Sci., 49(6):1478-1488.

STAHLY, T.S., CROMWELL, G.L., AVIOTTI, M. P. 1979. The effect of environmental temperature and dietary lysine source and level on the performance and carcass characteristics of growing swine. J. Anim. Sci., 49(5):1242-1251.

STAMATARIS, C., KYRIAZAKIS, I., EMMANS, G.C. 1991. The performance and body composition of young pigs following a period of growth retardation by food restriction. Anim. Prod., 53(2):373-381.

UNIVERSIDADE FEDERAL DE VIÇOSA. 1982. Central de Processamento de Dados - UFV - CPD. SAEG. Sistemas para análises estatísticas e genéticas. Viçosa, MG. 59p.

Recebido em: 18/11/98

Aceito em: 18/03/99 